\title{
Effect of restoration of euthyroidism on visfatin concentrations and body composition in women
}

\author{
Nadia Sawicka-Gutaj', Ariadna Zybek-Kocik' ${ }^{1}$ Michał Kloska², Paulina Ziółkowska' ${ }^{1}$, Agata Czarnywojtek ${ }^{3}$, \\ Jerzy Sowiński ${ }^{1}$, Dorota Mańkowska-Wierzbicka ${ }^{4}$ and Marek Ruchała ${ }^{1}$ \\ 'Department of Endocrinology, Metabolism and Internal Medicine, Poznan University of Medical Sciences, Poznan, Poland \\ ¿Lehigh Valley Health Network, Department of Medicine, Lehigh Valley Hospital - Cedar Crest, Allentown, USA \\ ${ }^{3}$ Department of Pharmacology, Poznan University of Medical Sciences, Poznan, Poland \\ ${ }^{4}$ Department of Gastroenterology, Internal Medicine, Metabolic Diseases and Dietetics, Poznan University of Medical Sciences, Poznan, Poland \\ Correspondence should be addressed to N Sawicka-Gutaj: nsawicka@ump.edu.pl
}

\begin{abstract}
Dysregulation of thyroid function has known impact on body metabolism, however, data regarding metabolic outcome after restoration of thyroid function is limited. Therefore, the aim of the study was to investigate the effect of restoration of euthyroidism on serum visfatin, and its associations with insulin resistance and body composition. This is an observational study with consecutive enrollment. Forty-nine hyperthyroid (median age of 34 years) and 44 hypothyroid women (median age of 46 years) completed the study. Laboratory parameters and body composition analysis were assessed before and after the therapy. In the hyperthyroid group, visfatin concentrations increased $(P<0.0001)$, while glucose concentrations decreased $(P<0.0001)$. Total body mass and fat mass in the

\section{Key Words}

- Hashimoto's disease

- Graves' disease

- nicotinamide phosphoribosyltransferase

- pre-B-cell colony enhancing factor

- fat tissue

- visfatin trunk and limbs significantly increased during the treatment. In the hypothyroid group, significant weight loss resulted from decrease of fat and muscle masses in trunk and limbs. Visfatin serum concentrations positively correlated with total fat mass $(r=0.19, P=0.01)$ and insulin concentrations ( $r=0.17, P=0.018$ ). In conclusion, restoration of thyroid function is not associated with beneficial changes in body composition, especially among hyperthyroid females.

\section{Introduction}

The adipose tissue is a well-established source of multiple circulating peptides that are responsible for various metabolic effects (1). Visfatin/NAMPT (nicotinamide phosphoribosyltransferase) has been recently recognized as an important adipocytokine with regulatory, immunomodulating and proinflammatory properties and has been broadly studied in metabolic disorders, neoplasms, and inflammatory conditions (2, 3, 4, 5). Thyroid hormones also profoundly affect thermogenesis, metabolic rate, food intake and energy expenditure (6). Thus, both hypo- and hyperthyroidism significantly alter these processes, resulting in significant changes in body composition $(7,8)$. Moreover, many thyroid disorders are associated with chronic inflammation, with the latter altering systemic response independently of thyroid hormones $(9,10)$.

Visfatin overexpression in thyroid cancers and in thyroid glands of patients with Graves' orbitopathy, as well as in their leukocytes, supporting anti-apoptotic and proinflammatory properties of this adipocytokine has been recently reported $(11,12,13)$. In addition, visfatin serum concentrations in hypothyroidism are associated with free thyroid hormones and antithyroperoxidase antibodies, while in hyperthyroidism visfatin mainly correlates with fat content with minor effect of thyroid autoimmunity $(14,15)$. However, previous studies on changes in visfatin serum concentrations in thyroid disorders brought inconclusive results, which might be

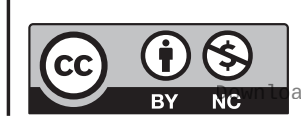


partially explained by the heterogenousity of thyroid disorders $(16,17,18,19,20)$.

Therefore, the aim of the study was to investigate the effect of restoration of euthyroidism on serum visfatin in severe thyroid dysfunction, and its relationship with insulin resistance and body composition. To limit the interference of individual factors, changes in three different thyrometabolic states in the same patients were also analysed.

\section{Patients and methods}

\section{Study design and patient enrollment}

This was an observational study with consecutive enrollment. Females with newly diagnosed overt autoimmune hypo- or hyperthyroidism (Hashimoto's disease or Graves' disease, respectively) were included. Inclusion criteria for hypothyroid group consisted of age $\geq 18$ years old, the elevation of TSH with a decrease of free thyroxine, and the elevation of antithyroperoxidase antibodies with features of Hashimoto's thyroiditis in ultrasound examination of the thyroid gland. Females with decreased TSH concentrations with elevation of free thyroxine, free triiodothyronine concentrations, and TSH-receptor autoantibodies were included in the hyperthyroid group. The diagnoses of hyper- and hypothyroidism, as well as Graves' or Hashimoto's disease, were made according to current recommendations, and were based on physical and biochemical examination (21, 22). Also, all patients were treated according to guidelinebased therapy: patients with hyperthyroidism received methimazole, some of them were treated with radioiodine (RAI). These females who developed hypothyroidism after RAI administration and patients with Hashimoto's disease became euthyroid on levothyroxine substitution.
Exclusion criteria were: acute or chronic diseases, medications, other autoimmune diseases, infections, potentially affecting body composition or visfatin concentrations.

Initially, 105 females were enrolled in the study: 52 with newly diagnosed hyperthyroidism in the course of Graves' disease and 53 with naive hypothyroidism caused by Hashimoto thyroiditis. Twelve women were lost to follow-up (Fig. 1 presents the study flow chart). Forty nine hyperthyroid females with a median age of 34 years (25th-75th percentile: 25-48 years) and forty four hypothyroid females with a median age of 46 years (25th-75th percentile: 33-52 years) achieved euthyroidism and completed the study. A median observation time was 12 months (25th-75th percentile: $11-13$ months) in a hyperthyroid group and ten months (25th-75th percentile: 9-11 months) in hypothyroid group at least 6 months after the restoration of euthyroidism in each patient. Fifteen hyperthyroid women developed hypothyroidism after RAI therapy and underwent evaluation three times: in hyper-, hypo- and euthyroid states.

The study was approved by the Ethical Committee of Poznan University of Medical Sciences and all patients signed an informed consent. The study adheres to the Declaration of Helsinki for ethical studies.

\section{Laboratory measurements}

Serum concentrations of visfatin, TSH (thyroidstimulating hormone), FT4 (free thyroxine), FT3 (free triiodothyronine), TPOAbs (anti-thyroperoxidase antibodies), fasting glucose and insulin were measured in each patient before and after restoration of thyroid function. Thyrotropin receptor antibodies (TRAbs) were assessed in the hyperthyroid group before the onset of therapy and when the euthyroidism was anticipated. ELISA Assay Kit from Phoenix Pharmaceuticals was used to
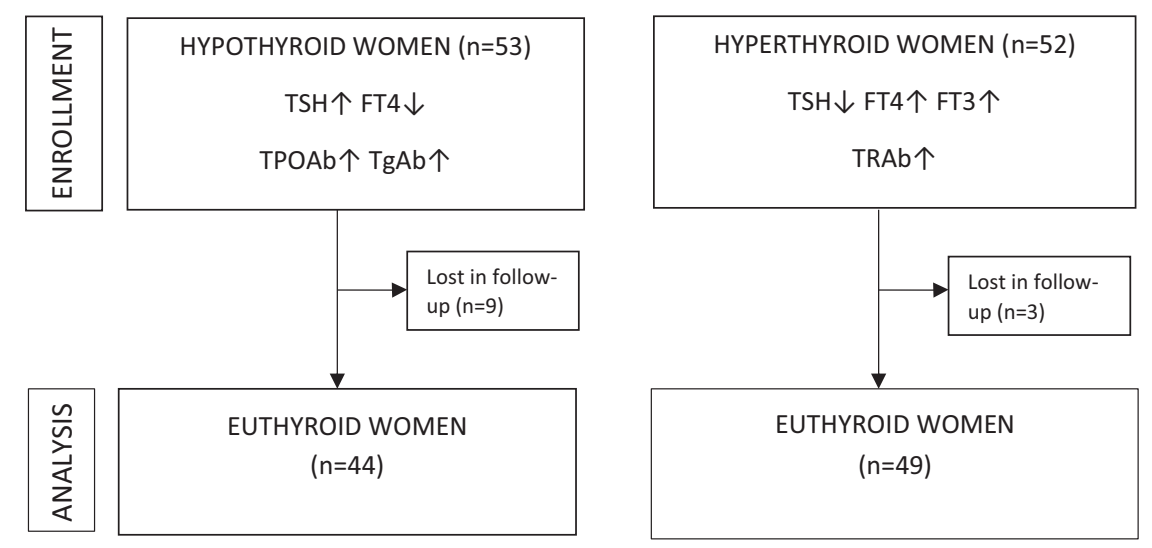

Figure 1

The study flow chart. (c) 2021 The authors Published by Bioscientifica Ltd
This work is licensed under a Creative Commons Attribution-NonCommercial 4.0 International License. ded from Bioscientifica.com at 04/26/2023 11:08:05AM via free access 
assess visfatin concentrations. Electrochemiluminescence technique was applied for estimation of TSH, FT4, FT3 concentrations (normal ranges: TSH 0.27-4.2 mU/L; FT4 11.5-21.0 pmol/L; FT3 3.9-6.7 pmol/L). TRAb titers were measured with the use of RIA TRAK Human Brahms (normal $<2$ IU/L). TPOAbs was assessed by RIA (normal range: <34 $\mathrm{IU} / \mathrm{mL})$. Glucose concentrations were estimated using Hitachi Cobas e601 chemiluminescent analyser (Roche Diagnostics) and insulin concentration was assessed using the ELISA kit from Phoenix Pharmaceuticals. HOMA-IR (Homeostatic Model Assessment of Insulin Resistance) was calculated to estimate insulin resistance. All patients were assessed before and after the therapy. In addition, hyperthyroid females who received RAI were assessed in hypothyroid state.

\section{Body composition analysis}

Body composition measurements were performed with the total body bioimpedance analyser Tanita MC 180 MA II (Tanita, Japan) in all patients before and after restoration of thyroid function. Similar to laboratory assessment, body composition in hyperthyroid females treated with RAI was also performed in hypothyroid state.

\section{Statistical analysis}

Statistical analysis was performed with MedCalc Statistical Software version 18.10 (MedCalc Software bvba, Ostend, Belgium; http://www.medcalc.org; 2018). Sobel Test Calculator (DanielSoper.com) was used to perform the mediation analysis. Normality was analysed by the D'Agostino-Pearson test. Since data did not follow normal distribution, comparison of the analysed parameters within groups before and after restoration of thyroid function was performed using the nonparametric Wilcoxon test for paired data. Changes of analysed parameters in the subgroup of hyperthyroid women who underwent assessment three times (in hyperthyroid, hypothyroid and euthyroid state) were investigated with the nonparametric Friedman test with the Conover post hoc multiple comparison tests. Comparison of results between hyper- and hypothyroid women was performed with the Mann-Whitney test. Spearman rank test was applied to find associations between analysed parameters. Sobel Test Calculator was used to assess the significance of mediation: TSH was independent variable, visfatin was dependent variable, while total fat mass and insulin were mediators. $P$ value $<0.05$ was considered statistically significant.

\section{Results}

\section{Effects of therapy on hormonal and metabolic status}

Hormonal and metabolic parameters are compared in Table 1.

\section{Hyperthyroid women}

TSH concentrations significantly increased and free thyroid hormones concentrations decreased after the therapy. Also, glucose concentrations decreased after restoration of thyroid function, while insulin concentrations remained unaltered. Visfatin concentrations increased when euthyroidism was achieved (Fig. 2B). No associations between visfatin and other biochemical parameters have been observed.

\section{Hypothyroid women}

TSH concentrations and TPOAbs decreased significantly, while free thyroid hormones increased after the therapy. Glucose and insulin concentrations, as well as visfatin (Fig. 2A) did not change. Visfatin serum concentrations positively correlated with TPOAbs in both hypo- and euthyroidism $(r=0.535, P=0.0002 ; r=0.0026, P=0.0026$,

Table 1 Changes of biochemical parameters in the study groups before and after restoration of thyroid function.

\begin{tabular}{|c|c|c|c|}
\hline \multicolumn{4}{|c|}{ Hyperthyroidism } \\
\hline Median (25-75\%) & Before & After & $P$ \\
\hline $\mathrm{TSH}(\mu \mathrm{IU} / \mathrm{mL})$ & $0.01(0.0-0.1)$ & $1.45(0.98-2.4)$ & $<0.0001$ \\
\hline FT4 (pmol/L) & $60.6(35.4-86.6)$ & $16.7(14.9-18.9)$ & $<0.0001$ \\
\hline FT3 (pmol/L) & $24.4(16-32.4)$ & $4.4(4-5.1)$ & $<0.0001$ \\
\hline Glucose (mg/dL) & $97(90-101)$ & $88(86-95)$ & $<0.0001$ \\
\hline Insulin (mU/mL) & $9.3(5.8-15.7)$ & $9.3(8.6-11.5)$ & 0.60 \\
\hline HOMA-IR & $2.3(1.4-4.1)$ & $2.0(1.7-2.7)$ & 0.13 \\
\hline Visfatin (ng/mL) & $9.1(7.9-11.4)$ & $12.3(9.9-13.6)$ & $<0.0001$ \\
\hline
\end{tabular}

\begin{tabular}{|c|c|c|}
\hline \multicolumn{3}{|c|}{ Hypothyroidism } \\
\hline Before & After & $P$ \\
\hline $81.6(55.8-100)$ & $1.6(1-2.3)$ & $<0.0001$ \\
\hline $2.33(1.5-3.8)$ & 16.7 (15.3-19.7) & $<0.0001$ \\
\hline $0.94(0.7-1.6)$ & $5.0(4.2-5.8)$ & $<0.0001$ \\
\hline 89 (83-97) & $90(85-96)$ & 0.60 \\
\hline $6.7(4.6-8.9)$ & $6.8(5.3-8.7)$ & 0.47 \\
\hline $1.42(1-2)$ & $1.5(1.1-1.9)$ & 0.64 \\
\hline $9.32(8.50-0.86)$ & $9.1(8.13-11.21)$ & 0.93 \\
\hline
\end{tabular}

FT3, free triiodothyronine; FT4, free thyroxine; TSH, thyroid-stimulating hormone. 

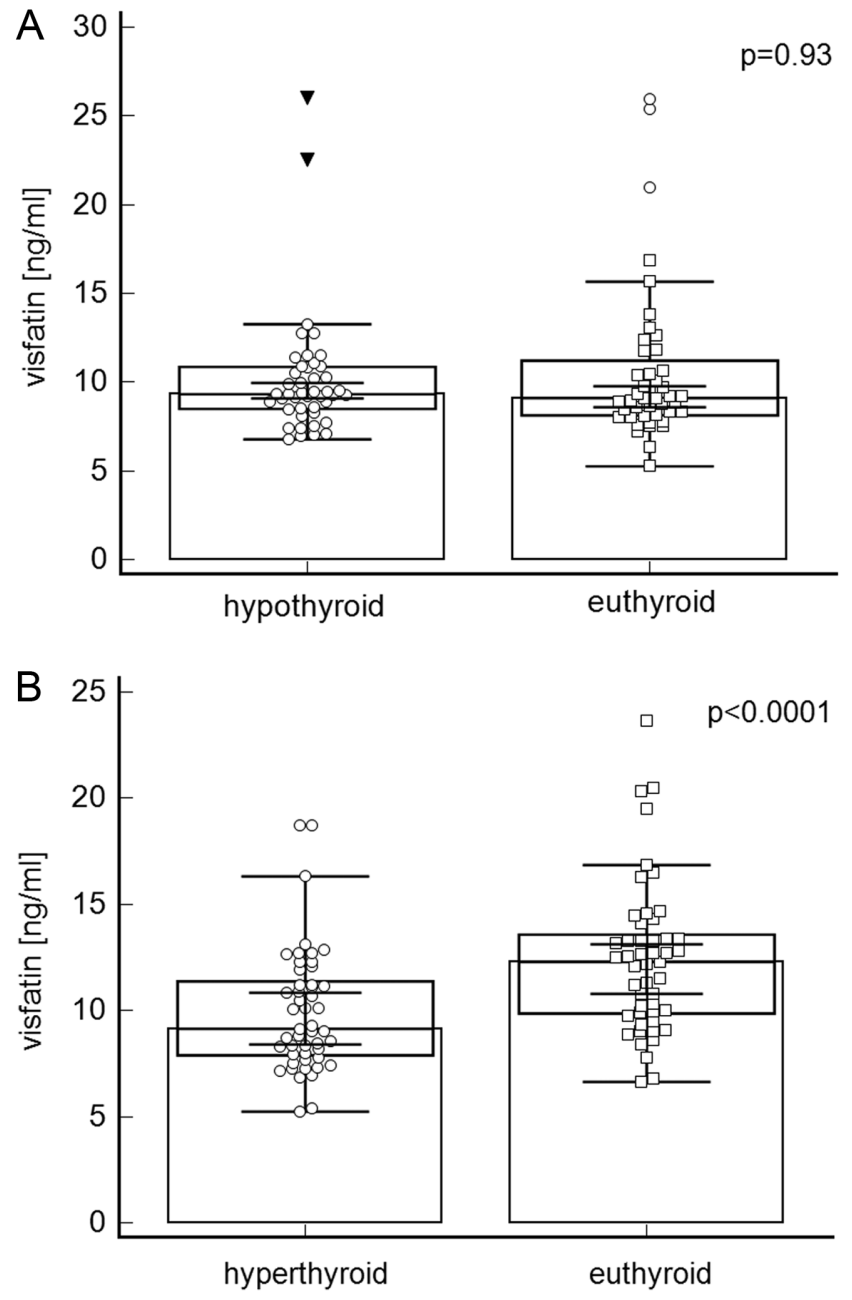

Figure 2

Changes of visfatin serum concentrations in hypo- (A) and hyperthyroid (B) groups.

respectively). In euthyroid phase, visfatin negatively correlated with FT3 $(r=-0.372 ; P=0.0141)$.

\section{Effects of therapy on body composition}

Results of body composition analyses are presented in Tables 2 and 3 .

\section{Hyperthyroid women}

Total body mass and fat mass significantly increased during the treatment. No significant change in total muscle mass was observed, while trunk muscle mass increased. Fat tissue increased in the trunk and limbs.

\section{Hypothyroid women}

Achievement of euthyroidism was associated with significant weight loss as a result of decrease of fat and muscle masses in trunk and limbs.

Hyperthyroid females had significantly lower body weight $(P=0.0034)$ and fat mass $(P=0.015)$ than hypothyroid females before the therapy was started, while muscle mass was similar at this time. When euthyroidism was reached, both groups did not differ with body weight, fat and muscle masses.

For pooled data of all women and all measurements, weak positive correlation between TSH concentrations and total body weight, as well as fat mass was found ( $r=0.19, P=0.01 ; r=0.2, P=0.006$, respectively). TSH concentrations were negatively associated with glucose and insulin $(r=-0.286, P=0.0001 ; r=-0.279, P=0.0001$, respectively). There was also inverse correlation between free thyroxine and free triiodothyronine and total body weight $(r=-0.246, P=0.0008 ; r=-0.17, P=0.022$, respectively) and fat mass $(r=-0.16, P=0.026 ; r=-0.18$, $P=0.018$, respectively), and positive correlation with glucose $(r=0.279, P=0.0001 ; r=0.303, P<0.0001$, respectively) and insulin $(r=0.252, P=0.0005 ; r=0.218$, $P=0.003$, respectively) concentrations. Muscle mass was not associated with TSH and thyroid hormones. Visfatin serum concentrations positively correlated with total fat mass $(r=0.19, P=0.01)$ and insulin concentrations $(r=0.17$, $P=0.018$ ) (Fig. 3), while there were no associations with body weight, fat trunk, muscle mass or TSH, free thyroid hormones, and glucose. All correlations are presented in Table 4. Total fat mass and insulin concentrations were found as factors mediating the association between TSH and visfatin $(P=0.0$ for both mediation analyses).

Table 2 Changes of body composition in hypo- and hyperthyroid females before and after restoration of thyroid function.

\begin{tabular}{|c|c|c|c|}
\hline \multicolumn{4}{|c|}{ Hyperthyroidism } \\
\hline Median (25-75\%) & Before & After & $P$ \\
\hline Body weight (kg) & $58.5(52.1-68.5)$ & $63.4(58.5-77.1)$ & $<0.0001$ \\
\hline $\mathrm{FC}(\%)$ & $24.6(19.4-28.8)$ & $28.9(24.4-34.2)$ & $<0.0001$ \\
\hline FM (kg) & $14.7(9.8-21.6)$ & $18.6(14.9-27.7)$ & $<0.0001$ \\
\hline FFM (kg) & $43.9(40.5-48.9)$ & 44.8 (39.9-49) & 0.065 \\
\hline MM (kg) & $42.3(39.3-46.8)$ & $43.3(39.8-47.9)$ & 0.19 \\
\hline
\end{tabular}

\begin{tabular}{lrrrr}
\hline \multicolumn{3}{c}{ Hypothyroidism } & \\
\hline \multicolumn{1}{c}{ Before } & & After & & \multicolumn{1}{c}{$P$} \\
\cline { 1 - 1 } $28.4(55.4-69.6)$ & & $64.7(59.2-74.6)$ & & $<0.0001$ \\
$19.2(15.7-23.2)$ & & $16.4(13.9-21.1)$ & & $<0.0001$ \\
$47.3(43.5-52.9)$ & & $46.5(42.5-50.4)$ & & $<0.0001$ \\
$44.6(41.3-50.2)$ & & $43.5(39.8-47.8)$ & & $<0.0001$ \\
\hline
\end{tabular}

FFM, free fat mass; FC, fat content; FM, fat mass; MM, muscle mass.

https://ec.bioscientifica.com

https://doi.org/10.1530/EC-21-0059 (c) 2021 The authors Published by Bioscientifica Ltd

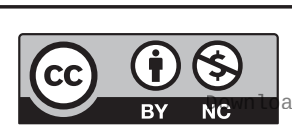

This work is licensed under a Creative Commons Attribution-NonCommercial 4.0 International License. ded from Bioscientifica.com at 04/26/2023 11:08:05AM via free access 
Table 3 Changes of fat and muscle distribution in hypo- and hyperthyroid females before and after restoration of thyroid function.

\begin{tabular}{|c|c|c|c|}
\hline \multicolumn{4}{|c|}{ Hyperthyroidism } \\
\hline Median (25-75\%) & Before & After & $P$ \\
\hline MM trunk (kg) & $23.9(22-26.9)$ & 25.6 (23.4-28.9) & 0.007 \\
\hline MM limbs (kg) & $18.0(16.6-20.7)$ & $18.1(14.7-20.4)$ & 0.02 \\
\hline FM trunk (kg) & $6.8(4.8-12.5)$ & $9.2(7.1-15.3)$ & $<0.0001$ \\
\hline FM limbs (kg) & $7.5(5.2-10.1)$ & $9.4(7-11.9)$ & $<0.0001$ \\
\hline VFI & $3(1-6)$ & $4(2-6)$ & $<0.0001$ \\
\hline
\end{tabular}

\begin{tabular}{|c|c|c|}
\hline \multicolumn{3}{|c|}{ Hypothyroidism } \\
\hline Before & After & $P$ \\
\hline $26.4(24-29.7)$ & 25.7 (22.6-27.9) & 0.0001 \\
\hline 18.3 (16.6-20.9) & $17.5(15.9-19.5)$ & 0.0012 \\
\hline $9.7(7.3-12.2)$ & $9.0(5.5-11)$ & 0.0001 \\
\hline $8.8(7.6-11.9)$ & $8.5(6.8-11.3)$ & 0.0003 \\
\hline $5(3-6)$ & $4(2-6)$ & $<0.0001$ \\
\hline
\end{tabular}

FM, fat mass; MM, muscle mass; VFI, visceral fat index.

\section{Changes in visfatin concentration and body} composition in three different thyrometabolic functional states in the hyperthyroid women who developed hypothyroidism after radioiodine therapy

A considerable increase in total body weight and visfatin concentrations in each patient, with the individual
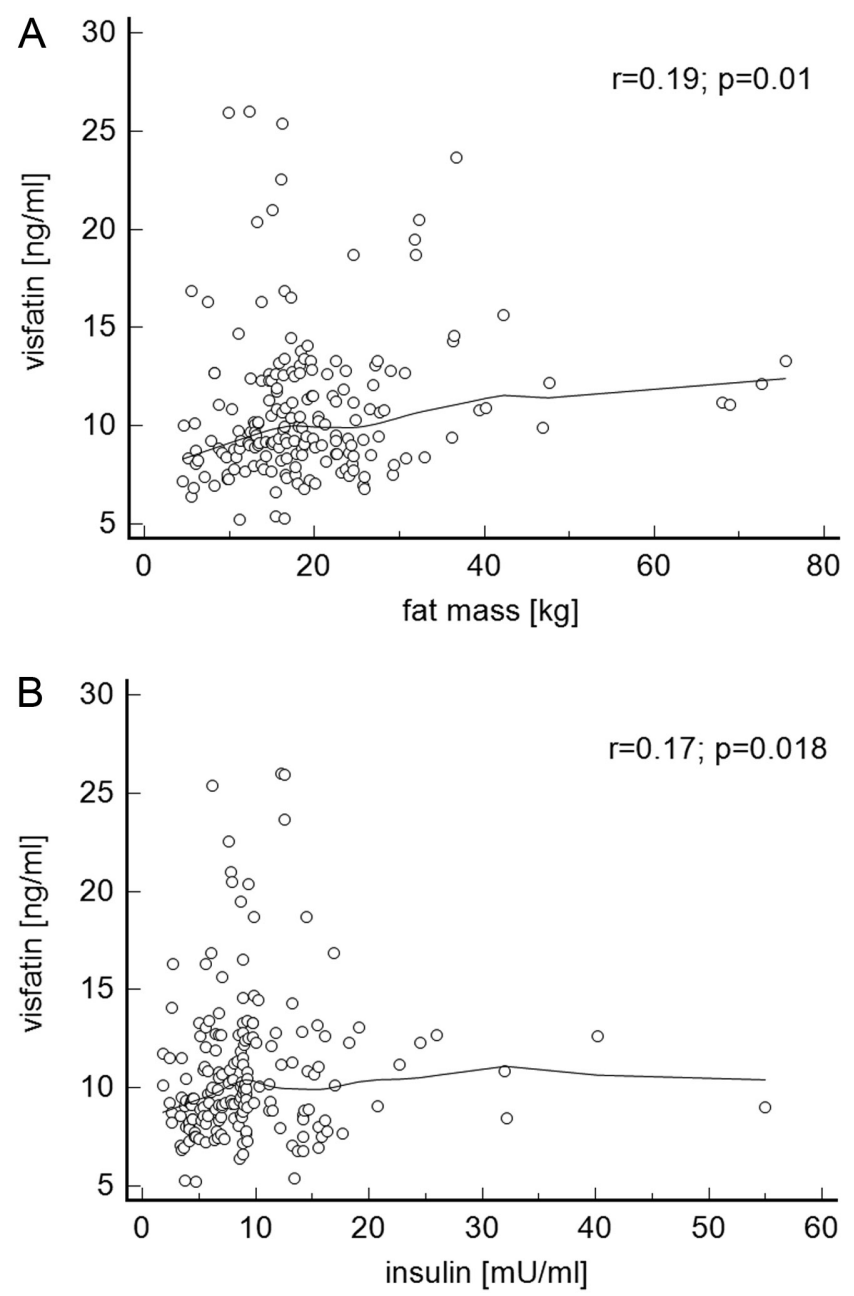

Figure 3

Relationship between visfatin serum concentrations and fat mass (A) and insulin (B) for pooled data of all measurements. differences between hyperthyroidism, hypothyrodism, and euthyroidism was observed $(P<0.0001)$ (Fig. 4A). The lowest fat mass was found in hyperthyroid state $(P<0.0001)$ and it increased during the study (Fig. 4B). Although fat mass tended to decrease when females achieved euthyroidism, no difference between hypothyroid and euthyroid states was found. In hypothyroidism, muscle mass decreased.

\section{Discussion}

The data about changes of body composition, especially in regional analysis, during anti-thyroid therapy is still scarce. This study clearly demonstrates alterations of body composition in patients with autoimmune thyroid disorders after restoration of euthyroidism. Hyperthyroid women in this cohort gained weight, with significant increase in fat mass in trunk and limbs, while muscle mass remained unaltered. This is consistent with

Table 4 Relationship between analysed parameters in pooled data of all women.

\begin{tabular}{|c|c|c|c|c|}
\hline & TSH & FT4 & FT3 & Visfatin \\
\hline $\begin{array}{l}\text { Body } \\
\text { weight }\end{array}$ & $\begin{array}{l}P=0.0121, \\
r=0.185\end{array}$ & $\begin{array}{l}P=0.0008 \\
r=-0.246\end{array}$ & $\begin{array}{l}P=0.0218, \\
r=-0.169\end{array}$ & $\begin{array}{l}P=0.9476 \\
r=-0.005\end{array}$ \\
\hline $\mathrm{FM}$ & $\begin{array}{l}P=0.0055, \\
r=0.203\end{array}$ & $\begin{array}{l}P=0.0256 \\
r=-0.164\end{array}$ & $\begin{array}{l}P=0.0179 \\
r=-0.169\end{array}$ & $\begin{array}{l}P=0.0097, \\
r=0.189\end{array}$ \\
\hline $\mathrm{MM}$ & $\begin{array}{l}P=0.2112 \\
r=0.0924\end{array}$ & $\begin{array}{l}P=0.0548 \\
r=-0.141\end{array}$ & $\begin{array}{l}P=0.1911 \\
r=-0.0974\end{array}$ & $\begin{array}{l}P=0.9871 \\
r=-0.001\end{array}$ \\
\hline Fat trunk & $\begin{array}{l}P=0.0749, \\
r=0.131\end{array}$ & $\begin{array}{l}P=0.0521 \\
r=-0.143\end{array}$ & $\begin{array}{l}P=0.0912 \\
r=-0.125\end{array}$ & $\begin{array}{l}P=0.1472 \\
r=0.107\end{array}$ \\
\hline Glucose & $\begin{array}{l}P=0.0001, \\
r=-0.286\end{array}$ & $\begin{array}{l}P=0.0001, \\
r=0.279\end{array}$ & $\begin{array}{l}P<0.0001, \\
r=0.303\end{array}$ & $\begin{array}{l}P=0.8942 \\
r=-0.009\end{array}$ \\
\hline Insulin & $\begin{array}{l}P=0.0157 \\
r=-0.177\end{array}$ & $\begin{array}{l}P=0.0005 \\
r=0.252\end{array}$ & $\begin{array}{l}P=0.003 \\
r=0.218\end{array}$ & $\begin{array}{l}P=0.0182, \\
r=0.173\end{array}$ \\
\hline $\mathrm{TSH}$ & - & - & - & $\begin{array}{l}P=0.5959, \\
r=0.0391\end{array}$ \\
\hline FT4 & - & - & - & $\begin{array}{l}P=0.7831 \\
r=-0.0203\end{array}$ \\
\hline FT3 & - & - & - & $\begin{array}{l}P=0.2808 \\
r=-0.0802\end{array}$ \\
\hline
\end{tabular}

$F M$, fat mass; FT3, free triiodothyronine; FT4, free thyroxine; MM, muscle mass; TSH, thyroid-stimulating hormone.

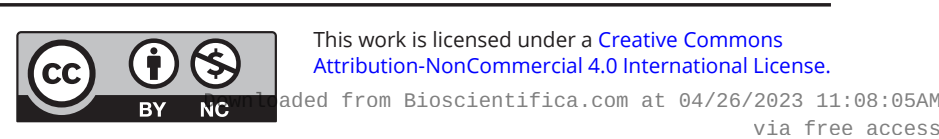



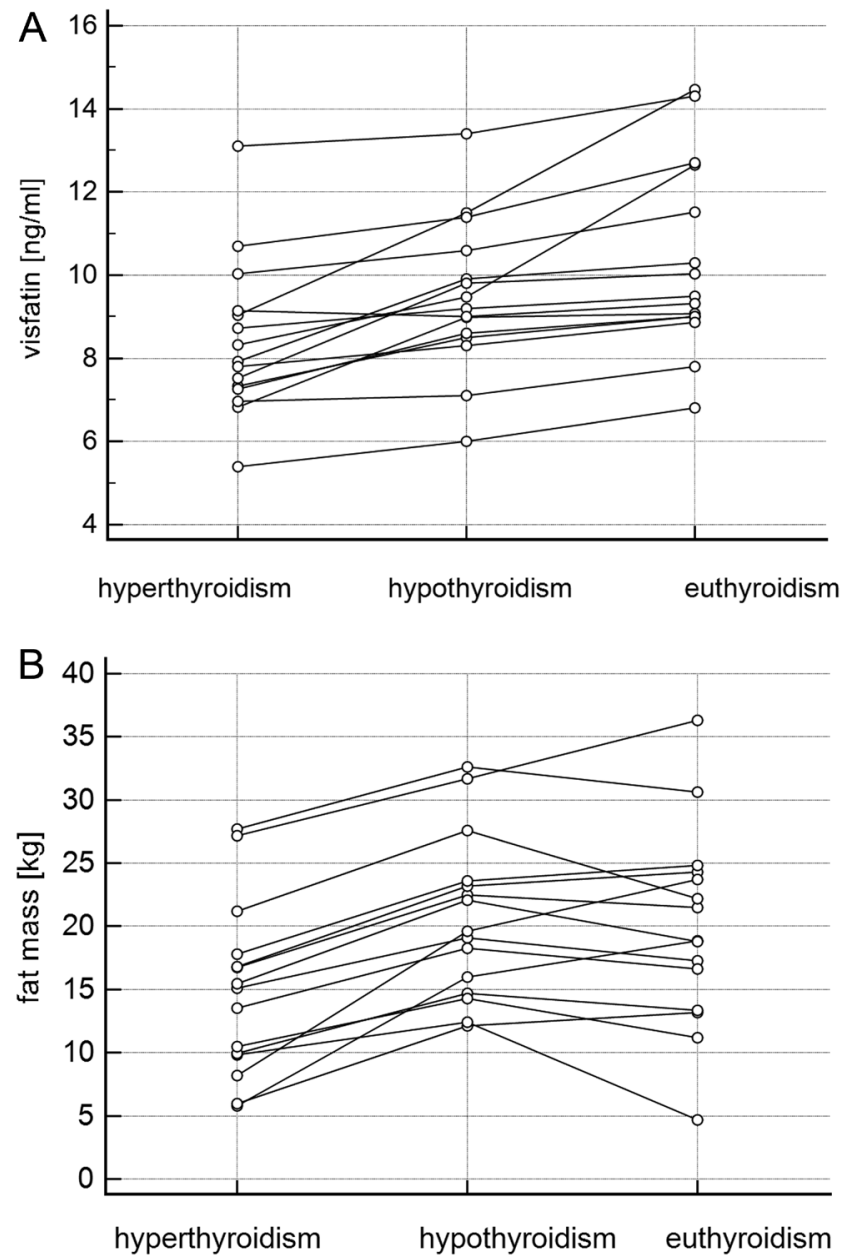

Figure 4

Individual visfatin (A) and fat mass (B) changes in the subgroup of hyperthyroid women who developed hypothyroidism after radioiodine therapy (each patient evaluated in hyperthyroidism, hypothyroidism, and euthyroidism).

previously reported studies showing increase in fat mass during restoration of thyroid function $(7,23)$. However, in contrast to our findings, so far available data reported increase in muscle mass when euthyroidism was achieved $(7,24)$. Interestingly, improvement in muscle strength has been observed even after the restoration of thyroid function in subclinical hyperthyroidism (24). Observed muscle weakness in hyperthyroid patients mainly results from changes in skeletal muscle metabolism, which may explain contradictive results in post therapeutic muscle mass analysis (25). This study investigated only women, and similar influence of normalization of thyroid function on body composition parameters, including fat and muscle masses in Graves' hyperthyroidism has been recently reported by other authors (26). In the hypothyroid females group, we observed loss of weight represented by the decrease of both fat and muscle mass which is consistent with findings observed by other authors $(7,27)$. Interestingly, one study reported that the decrease of body weight was caused mainly by the decrease of lean mass, while fat mass remained unaltered during the therapy (28). It is unclear how differences in physical activity during the therapy affected the results amongst studied group. Observed metabolic and anthropometric changes during the restoration of thyroid function in both hyper- and hypothyroid patients might not lead to normalization of energy expenditure after the therapy. Levothyroxine (LT4)-replacement therapy causing decrease of FT3 concentrations has been proved to be associated with lowering of FT3-dependent resting energy expenditure (29). Recent systemic review and meta-analysis found that normalization of TSH in LT4treated patients does not lead to sufficient decrease of low dose lipoprotein and total cholesterol concentrations (30). These effects might be clinically significant not only for treated hypothyroid patients, but also for hyperthyroid subjects who needed radical therapy with radioiodine or thyroidectomy followed by necessary of LT4 substitution. This complex interplay between thyroidrelated hormones and adipose tissue which secrets proinflammatory adipocytokines should be considered during the therapy of thyroid dysfunctions. Our findings might be interpreted in a broader context of increased longterm cardiovascular risk unrelated to hormonal status in patients with thyroid disorders (31). Therefore, prevention of unfavorable anthropometric changes observed during the therapy of thyroid dysfunctions could have beneficial metabolic effects.

Significant increase in fat mass in hyperthyroid females was followed by the increase in visfatin concentration after the treatment. Total body adiposity, was the major determinant of visfatin concentrations in females with thyroid dysfunctions of autoimmune origin, while fat trunk or visceral fat index did not correlate with visfatin (despite NAMPT) concentrations. This observation is consistent with other studies suggesting that also subcutaneous fat tissue might contribute to circulating visfatin concentrations $(32,33)$. Our findings might also explain contradictory results of previous data applying traditional methods for anthropometric assessment (i.e. BMI, waist-to-hip ratio, or skin fold) $(34,35)$. Furthermore, latest research revealed that serum visfatin correlates with TPOAbs in hypothyroid patients both in adults and children $(15,36)$. Similar to this study, Caixas et al. observed that in hyperthyroid patients fat mass increases during the therapy with concomitant increase of visfatin (16). The design of the study does

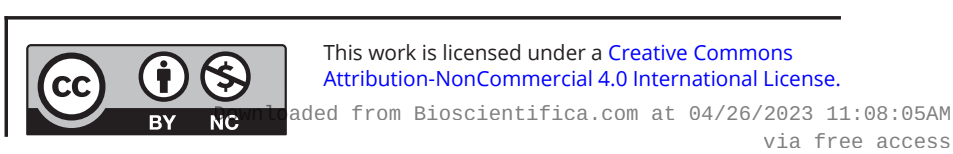


not enable to answer if observed visfatin changes during recovery in hyperthyroid females simply reflect increase of adiposity or is a result of a compensatory response involved in glucose and insulin regulation. As TSH receptor is expressed in adipocytes, observed changes might result from interplay between TSH receptor stimulation potentially leading to release of visfatin from fat tissue (37). In fact, the current study confirmed that both total fat mass and insulin concentrations are mediators significantly influencing the association between TSH and visfatin. In contrast to other authors, visfatin remained unchanged after recovery in hypothyroid women (16). Visfatin has been suggested to act as a myokine, and data suggests that levothyroxine substitution leads to increment of muscle mass (38). Moreover, significant decrease of muscle mass during the therapy was noticed, and this difference might explain the contradictory results.

The novelty of this study is the analysis of the link between visfatin, thyroid-related hormones and antithyroid antibodies, as well as with body composition parameters including fat content and muscle mass in trunk and limbs. Also, to the best of our knowledge, this is the first study investigating individual serum visfatin changes in three thyrometabolic states. The main limitation of this study is the observational design which did not enable to make definite conclusions. Furthermore, the use of the bioimpedance method for body composition analysis is not precise as dual-energy X-ray absorptiometry (DXA). However, accuracy of bioimpedance has been proved in several studies, also among patients with thyroid dysfunctions (39). What more, strict inclusion and exclusion criteria were applied, which allowed to avoid factors potentially blinding the results. Also, the same patients were followed during the therapy, which limited the influence of individual factors.

\section{Conclusion and future perspectives}

Restoration of thyroid function in hyperthyroid females was followed by the significant increase of fat mass and visfatin concentrations. In hypothyroid women, fat and muscle masses decreased after therapy. All of observed alteration of body composition might have negative influence on energy expenditure in euthyroid patients. Based on our results, one could speculate that currently recommended hormonal goals of the therapy of thyroid dysfunctions should be extended by the additional clinical parameters, such as body weight and fat mass. Therefore, future interventional studies should investigate the effect of physical activity on body composition changes during the therapy of severe thyroid dysfunctions (40).

\section{Declaration of interest}

The authors declare that there is no conflict of interest that could be perceived as prejudicing the impartiality of the research reported.

\section{Funding}

This study was partially funded by The National Science Centre in Poland grant nr DEC-2012/07/N/NZ5/01736. The study was also supported by Polpharma Scientific Fundation.

\section{Author contribution statement}

Ariadna Zybek-Kocik, Michał Kloska and Paulina Ziółkowska contributed equally to this work.

\section{References}

1 Choe SS, Huh JY, Hwang IJ, Kim JI \& Kim JB. Adipose tissue remodeling: its role in energy metabolism and metabolic disorders. Frontiers in Endocrinology 20167 30. (https://doi.org/10.3389/ fendo.2016.00030)

2 Baranowska-Bik A, Uchman D, Litwiniuk A, Kalisz MG, Martynska L, Baranowska BA, Bik W \& Kochanowski J. Peripheral levels of selected adipokines in patients with newly diagnosed multiple sclerosis. Endokrynologia Polska 202071 109-115. (https://doi.org/10.5603/ EP.a2020.0008)

3 Chwalba A, Machura E, Ziora K \& Ziora D. The role of adipokines in the pathogenesis and course of selected respiratory diseases. Endokrynologia Polska 201970 504-510. (https://doi.org/10.5603/ EP.a2019.0051)

4 Kazimierczak-Kabzinska A, Kajdaniuk D, Sieminska L, Nowak M, Glogowska-Szelag J, Borgiel-Marek H, Janyga Sz, Kos-Kudla B \& Marek B. Selected adipose tissue hormones in the blood of patients with ischaemic cerebral stroke. Endokrynologia Polska 202071 21-26. (https://doi.org/10.5603/EP.a2019.0057)

5 Dalamaga M \& Christodoulatos GS. Visfatin, obesity, and cancer. In Adipocytokines, Energy Balance, and Cancer, pp. 109-136. Springer, 2017.

6 Yavuz S, Salgado Nunez del Prado S \& Celi FS. Thyroid hormone action and energy expenditure. Journal of the Endocrine Society 20193 1345-1356. (https://doi.org/10.1210/js.2018-00423)

7 Stangierski A, Ruchala M, Krauze T, Moczko J \& Guzik P. Treatment of severe thyroid function disorders and changes in body composition. Endokrynologia Polska 201667 359-366. (https://doi.org/10.5603/ EP.a2016.0025)

8 Jacobsen R, Lundsgaard C, Lorenzen J, Toubro S, Perrild H, Krog-Mikkelsen I \& Astrup A. Subnormal energy expenditure: a putative causal factor in the weight gain induced by treatment of hyperthyroidism. Diabetes, Obesity and Metabolism 20068 220-227. (https://doi.org/10.1111/j.1463-1326.2005.00486.x)

9 Owecki M, Sawicka-Gutaj N, Owecki MK, Ambrosius W, Dorszewska J, Oczkowska A, Michalak M, Fischbach J, Kozubski W \& Ruchala M. Pulsatility index in carotid arteries is increased in levothyroxine-treated Hashimoto disease. Hormone and Metabolic Research 201547 577-580. (https://doi.org/10.1055/s-0034-1398491)

10 Carbotta G, Tartaglia F, Giuliani A, Carbotta S, Tromba L, Jacomelli I, De Anna L \& Fumarola A. Cardiovascular risk in chronic autoimmune thyroiditis and subclinical hypothyroidism patients. A cluster analysis. International Journal of Cardiology 2017230 115-119. (https://doi.org/10.1016/j.ijcard.2016.12.066) 
11 Sawicka-Gutaj N, Waligórska-Stachura J, Andrusiewicz M, Biczysko M, Sowiński J, Skrobisz J \& Ruchała M. Nicotinamide phosphorybosiltransferase overexpression in thyroid malignancies and its correlation with tumor stage and with survivin/survivin DEx3 expression. Tumour Biology 201536 7859-7863. (https://doi. org/10.1007/s13277-015-3506-z)

12 Sawicka-Gutaj N, Andrusiewicz M, Czarnywojtek A, WaligórskaStachura J, Biczysko M, Skrobisz J, Sowiński J \& Ruchała M. Changes of nicotinamide phosphoribosyltransferase expressions in thyroid glands of patients with different thyroid pathologies. BioMed Research International 20182018 1316390. (https://doi. org/10.1155/2018/1316390)

13 Sawicka-Gutaj N, Budny B, Zybek-Kocik A, Sowiński J, Ziemnicka K, Waligórska-Stachura J \& Ruchała M. Nicotinamide phosphoribosyltransferase leukocyte overexpression in Graves opthalmopathy. Endocrine 201653 497-504. (https://doi. org/10.1007/s12020-015-0855-8)

14 Sawicka-Gutaj N, Zybek-Kocik A, Kloska M, Czarnywojtek A, Sowiński J, Budny B, Woliński K, Ziemnicka K, MańkowskaWierzbicka D \& Ruchała M. Determinants of visfatin/NAMPT serum concentration and its leukocyte expression in hyperthyroidism. Hormone and Metabolic Research 201850 653-660. (https://doi. org/10.1055/a-0669-1584)

15 Sawicka-Gutaj N, Zybek-Kocik A, Klimowicz A, Kloska M, Mankowska-Wierzbicka D, Sowinski J \& Ruchala M. Circulating visfatin in hypothyroidism is associated with free thyroid hormones and antithyroperoxidase antibodies. International Journal of Endocrinology 20162016 7402469. (https://doi. org/10.1155/2016/7402469)

16 Caixas A, Tirado R, Vendrell J, Gallart L, Megia A, Simon I, Llaurado G, Gonzalez-Clemente JM \& Gimenez-Palop O. Plasma visfatin concentrations increase in both hyper and hypothyroid subjects after normalization of thyroid function and are not related to insulin resistance, anthropometric or inflammatory parameters. Clinical Endocrinology 200971 733-738. (https://doi.org/10.1111/ j.1365-2265.2009.03546.x)

17 Chu CH, Lee JK, Wang MC, Lu CC, Sun CC, Chuang MJ \& Lam HC. Change of visfatin, C-reactive protein concentrations, and insulin sensitivity in patients with hyperthyroidism. Metabolism: Clinical and Experimental 200857 1380-1383. (https://doi.org/10.1016/j. metabol.2008.05.006)

18 Ozkaya M, Sahin M, Cakal E, Yuzbasioglu F, Sezer K, Kilinc M \& Simsek Imrek SS. Visfatin plasma concentrations in patients with hyperthyroidism and hypothyroidism before and after control of thyroid function. Journal of Endocrinological Investigation 200932 435-439. (https://doi.org/10.1007/BF03346482)

19 Han J, Zhang TO, Xiao WH, Chang CQ \& Ai H. Up-regulation of visfatin expression in subjects with hyperthyroidism and hypothyroidism is partially relevant to a nonlinear regulation mechanism between visfatin and tri-iodothyronine with various concentrations. Chinese Medical Journal 2012125 874-881. (https:// doi.org/10.3760/cma.j.issn.0366-6999.2012.05.026)

20 Yildiz U, Bukan N, Aktas B \& Toruner F. The relationship between thyroid function and serum levels of angiopoietin-like protein 3 leptin and visfatin. Acta Endocrinologica 20139 171-180. (https://doi. org/10.4183/aeb.2013.171)

21 Okosieme O, Gilbert J, Abraham P, Boelaert K, Dayan C, Gurnell M, Leese G, McCabe Ch, Perros P, Smith V, et al. Management of primary hypothyroidism: statement by the British Thyroid Association Executive Committee. Clinical Endocrinology 201684 799-808. (https://doi.org/10.1111/cen.12824)

22 Kahaly GJ, Bartalena L, Hegedus L, Leenhardt L, Poppe K \& Pearce SH. European Thyroid Association guideline for the management of Grave's hyperthyroidism. European Thyroid Journal 20187 167-186. (https://doi.org/10.1159/000490384)
23 Kyriacou A, Kyriacou A, Makris KC, Syed AA \& Perros P. Weight gain following treatment of hyperthyroidism - a forgotten tale. Clinical Obesity 20199 e12328. (https://doi.org/10.1111/cob.12328)

24 Brennan MD, Powell C, Kaufman KR, Sun PC, Bahn RS \& Nair KS. The impact of overt and subclinical hyperthyroidism on skeletal muscle. Thyroid 200616 375-380. (https://doi.org/10.1089/ thy.2006.16.375)

25 Brennan MD, Coenen-Schimke JM, Bigelow ML \& Nair KS. Changes in skeletal muscle protein metabolism and myosin heavy chain isoform messenger ribonucleic acid abundance after treatment of hyperthyroidism. Journal of Clinical Endocrinology and Metabolism 200691 4650-4656. (https://doi.org/10.1210/jc.2006-1074)

26 Chng CL, Lim AYY, Tan HC, Kovalik JP, Tham KW, Bee YM, Lim W, Acharyya S, Lai OF, Chong MF, et al. Physiological and metabolic changes during the transition from hyperthyroidism to euthyroidism in Graves' disease. Thyroid 201626 1422-1430. (https://doi. org/10.1089/thy.2015.0602)

27 Sanchez A, Carretto H, Ulla MR \& Capozza R. Body composition of patients with primary hypothyroidism evaluated by dualenergy X-ray absorptiometry and its changes after treatment with levo-thyroxine. Endocrinologist 200414 321-327. (https://doi. org/10.1097/01.ten.0000146570.51516.5b)

28 Karmisholt J, Andersen S \& Laurberg P. Weight loss after therapy of hypothyroidism is mainly caused by excretion of excess body water associated with myxoedema. Journal of Clinical Endocrinology and Metabolism 201196 E99-E103. (https://doi.org/10.1210/ jc.2010-1521)

29 Samuels MH, Kolobova I, Smeraglio A, Peters D, Purnell JQ \& Schuff KG. Effects of levothyroxine replacement or suppressive therapy on energy expenditure and body composition. Thyroid 2016 26 347-355. (https://doi.org/10.1089/thy.2015.0345)

30 McAninch EA, Rajan KB, Miller CH \& Bianco AC. Systemic thyroid hormone status during levothyroxine therapy in hypothyroidism: a systematic review and meta-analysis. Journal of Clinical Endocrinology and Metabolism 2018103 4533-4542. (https://doi.org/10.1210/ jc.2018-01361)

31 Brandt F, Thvilum M, Almind D, Christensen K, Green A, Hegedus L \& Brix TH. Graves' disease and toxic nodular goiter are both associated with increased mortality but differ with respect to the cause of death: a Danish population-based register study. Thyroid 201323 408-413. (https://doi.org/10.1089/thy.2012.0500)

32 Berndt J, Kloting N, Kralisch S, Kovacs P, Fasshauer M, Schon MR, Stumvoll M \& Bluher M. Plasma visfatin concentrations and fat depot-specific mRNA expression in humans. Diabetes $2005 \mathbf{5 4}$ 2911-2916. (https://doi.org/10.2337/diabetes.54.10.2911)

33 Klimontov V, Bulumbaeva D, Bgatova NP, Taskaeva I, Fazullina O, Orlov N, Korbut AI, Savchenko S \& Konenkov V. The relationships between serum levels of adipokines, body fat distribution, and subcutaneous microvasculature in type 2 diabetic subjects. Diabetes. 201867 (Suppl 1) abstract 2055-P. (https://doi. org/10.2337/db18-2055-P)

34 Willers SM, Brunekreef B, Abrahamse-Berkeveld M, Van De Heijning B, Van Der Beek E, Postma DS, Kerkhof M, Smit HA \& Wijga AH. Serum visfatin and leptin in relation to childhood adiposity and body fat distribution: the PIAMA birth cohort study. Annals of Nutrition and Metabolism 201566 63-71. (https://doi. org/10.1159/000369979)

35 Dogru T, Sonmez A, Tasci I, Bozoglu E, Yilmaz MI, Genc H, Erdem G, Gok M, Bingol N, Kilic S, et al. Plasma visfatin levels in patients with newly diagnosed and untreated type 2 diabetes mellitus and impaired glucose tolerance. Diabetes Research and Clinical Practice 200776 24-29. (https://doi.org/10.1016/j.diabres.2006.07.031)

36 Farghaly HS, Metwalley KA, Ahmed FA, Raafat DM, El-Asheer O, Ali AM, Bahdawy A \& Zahran AM. Visfatin level in children and adolescents with autoimmune thyroiditis. Therapeutic Advances https://ec.bioscientifica.com https://doi.org/10.1530/EC-21-0059
(C) 2021 The authors Published by Bioscientifica Ltd

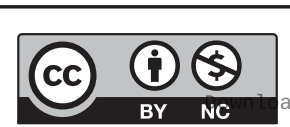

This work is licensed under a Creative Commons Attribution-NonCommercial 4.0 International License. ded from Bioscientifica.com at 04/26/2023 11:08:05AM 
in Endocrinology and Metabolism 20178 119-125. (https://doi. org/10.1177/2042018817731073)

37 Briet C, Suteau-Courant V, Munier M \& Rodien P. Thyrotropin receptor, still much to be learned from the patients. Best Practice and Research: Clinical Endocrinology and Metabolism 201832 155-164. (https://doi.org/10.1016/j.beem.2018.03.002)

38 Krzysik-Walker SM, Ocon-Grove OM, Maddineni SR, Hendricks III GL \& Ramachandran R. Is visfatin an adipokine or myokine? Evidence for greater visfatin expression in skeletal muscle than visceral fat in chickens. Endocrinology 2008149 1543-1550. (https:// doi.org/10.1210/en.2007-1301)

39 Sartorio A, Ferrero S, Trecate L \& Bedogni G. Thyroid function is more strongly associated with body impedance than anthropometry in healthy subjects. Journal of Endocrinological Investigation 200225 620-623. (https://doi.org/10.1007/BF03345086)

40 Kowalska MG, Fehlau M, Cymerys M \& Pa G. A thousand words about running fitness tests. Journal of Medical Science $2019 \mathbf{8 8}$ 184-191. (https://doi.org/10.20883/jms.344)

Received in final form 25 February 2021

Accepted 24 March 2021

Accepted Manuscript published online 25 March 2021
This work is licensed under a Creative Commons Attribution-NonCommercial 4.0 International License. 